\title{
Assessment of the manufacturability of construction products in the renovation zone
}

\author{
Pavel Oleinik*
}

Moscow State University of Civil Engineering, Yaroslavskoe shosse, 26, Moscow, 129337, Russia

\begin{abstract}
Nowadays, the large-scale development of the renovation of the housing stock of cities includes not only the reconstruction of residential areas, but also the actively expanding renovation of industrial zones. Moreover, each renovation area is characterized by a wide variety of residential and non-residential buildings, urban infrastructure facilities. According to the structure of renovation objects, eight main zones have been identified, which include various combinations of the above objects. At the same time, in the process of work, it is necessary to constantly monitor the compliance of technology regulations with the design values of the quality of construction products. For this, in order to assess both individual groups of objects and buildings and structures for the renovation zone in general, a system of manufacturability indicators is proposed. As a basic indicator, labor costs (machine time) are recommended, since it is the changes in the technology of work that immediately affect the work of construction teams and their links. The conditions are given under which it is possible to assert the compliance or non-compliance of the applied technological regulations with the design requirements. The sequence of establishing an integral indicator of the manufacturability of construction products during the period of their creation in the whole renovation zone is described.
\end{abstract}

\section{Introduction}

Nowadays, the renovation of residential areas is being actively carried out in Moscow, St. Petersburg and other cities. First of all, residential areas are being renovated, in which there are emergency buildings, five-storey standard buildings built in 1958-1970, as well as residential buildings with a high degree of physical deterioration of more than $70 \%$. These and other residential buildings that do not comply with modern urban planning regulations are subject to demolition [5].

\footnotetext{
* Corresponding author: cniomtp@mail.ru
} 


\section{Review}

In the process of preparing for a large-scale renovation of residential areas, foreign experience and domestic experience of the first reconstructed microdistricts of Moscow must be taken into account $[5,6]$.

The experience of European countries in housing renovation testifies, first of all, to the careful attitude towards buildings and structures that are more than a century old and are historical and architectural monuments. The facades of such buildings are repaired or restored with their full preservation, which allows keeping the historical appearance of streets and squares. At the same time, a modern layout and high comfort for residents are created inside the buildings. It should also be noted that the states, especially of Eastern Europe, spend a lot to revive the historical appearance of their cities and, first of all, their capitals. So, for example, in Budapest, Warsaw, Prague, etc., all buildings modeled by the type of the microdistricts of the Soviet Union in the form of five-story and nine-story buildings are being demolished and built up with unique buildings with historical or modern facades.

The beginning of the active demolition of five-storey buildings in Moscow was the release of the Decree of the Government of Moscow No. 735 dated September 6, 1994 "On priority measures to ensure the program of comprehensive reconstruction and modernization of five-storey residential buildings of the first industrial housing construction, the continuation of the reconstruction of buildings". As a result, more than 1,700 residential buildings were demolished in the first twenty years. In the process of implementing the decree, an approach was developed for the quarterly demolition of buildings, covering all non-commercial housing with the subsequent integrated development of the vacated territories. It is this approach that has become the basis for modern renovation of residential areas in Moscow and other cities.

The number of mandatory procedures for the effective renovation of residential areas includes, according to the experience of past years, the anticipatory implementation of a set of preparatory measures and works and the dismantling of all internal engineering systems of water supply, sewerage, gas supply, power supply, heat supply, ventilation and communications, including engineering equipment and devices, as well as finishing elements - removing window frames and doors with frames, built-in wardrobes and mezzanines, floor coverings, ceramic tiles from the walls. Experience has substantiated the need to abandon the mechanical collapse of building structures due to the large spread of pieces of destroyed structures, strong dust emission and noise generation, as well as a significant increase in labor intensity when sorting and transporting demolition products. Therefore, this method of demolition was replaced by the use of modern demolition excavators equipped with hydraulic shears, a hydraulic hammer, a bucket and a grab [5].

\section{Structure of renovation objects}

A powerful impetus for the revitalization of the renovation of residential areas in Moscow is the constant high demand for housing and, as the forecasts show, one territory of the renovated residential areas is already insufficient. In this regard, the renovation of residential areas is more and more intensively complemented by the renovation of industrial zones, including abandoned factories and warehouses, neglected and inefficiently used territories, industrial enterprises polluting the district. Such industrial zones occupy about 18.8 thousand hectares, which is about $17 \%$ of the territory of "old" Moscow.

On the territory of a number of such zones, modern residential complexes and new infrastructure facilities - preschool and school institutions, clinics, retail and entertainment centers, sports grounds, roads and driveways are already being built or will soon be built [4, 14]. In some of these territories, the organization of new industries is envisaged. For example, the renovation of the territory of the former "ZIL" includes the construction of a 
residential complex "ZILART" for 30 thousand residents with a cultural and business center, 12 kindergartens for 1000 children, three schools for 3 thousand pupils, a transport hub. An ice arena has already been built, a synchronized swimming center, a branch of the Hermitage, etc. are under construction.

According to the structure of renovation objects, the following main zones can be distinguished:

- territories with new residential buildings and new infrastructure facilities;

- territories with new and reconstructed residential buildings and infrastructure facilities;

- territories with residential buildings, new industrial enterprises and institutions with an updated infrastructure;

- territories with concentrated historical and architectural monuments;

- territories with mixed residential buildings, infrastructure, historical and architectural monuments;

- $\quad$ territories with renovated or new parks, squares and embankments;

- territories with unique buildings and structures;

- territories with objects of national importance.

It should be noted that at the stages of pre-design and design preparation of the renovation areas, a large and painstaking work is carried out on the development of urban planning documentation, including layouts of various types of construction, engineering support schemes for renovation territories, territorial planning projects, architectural and urban planning solutions, projects, working documentation. At the same time, local authorities, together with the developers of urban planning documentation, organize the publication of the main decisions taken and conduct appropriate discussions of the documentation materials with residents. The results of such discussions are then analyzed and, as a rule, most of the proposals of citizens, one way or another, are taken into account. After passing the examination, finalization and approval of urban planning documentation, an important period begins - the production of construction and installation work, the general task of which is the construction of buildings and structures of the renovation area with layout and structural indicators in full compliance with the design indicators $[1,8,13]$.

\section{Problem statement}

Each zone has its own characteristics, and the choice of solutions for its renovation requires an individual approach $[3,9,10,11]$. Almost any renovation zone can be viewed as a rather complex system in which almost all objects - residential buildings, enterprises and institutions, infrastructure facilities are in close interaction. In these conditions, an everincreasing role is assigned to the control of the manufacturability of the created construction products as a whole in the renovation zone as a measure of achieving the design quality of buildings and structures [2, 7, 12]. The indicator of the integral manufacturability of the facilities under construction in the renovation zone during the construction and installation work can be represented as a dependence, which, for example, for a territory with new and reconstructed residential buildings and infrastructure facilities will have the following form:

$$
P=f\left(P_{1}, P_{2}, P_{3}\right)
$$

where $P$ - integral indicator of manufacturability of construction products as a whole for the renovation zone;

$P_{1}, P_{2}, P_{3}$ - indicators of manufacturability of erected, reconstructed residential buildings, and infrastructure facilities, respectively. 
At the same time, the indicator of the manufacturability of the infrastructure $\left(P_{3}\right)$ should be expressed through its main components of the manufacturability of groups of objects, since such groups differ from each other both in terms of functional and design features.

$$
P_{3}=f\left(P_{3}^{1}, P_{3}^{2}, P_{3}^{3}, \ldots, P_{3}^{7}\right)
$$

where $P_{3}^{1}, P_{3}^{2}, P_{3}^{3}, P_{3}^{4}, P_{3}^{5}, P_{3}^{6}, P_{3}^{7}$ - indicators of manufacturability of erected preschool and school buildings, medical institutions, shopping and entertainment centers, consumer services, physical culture, social security, driveways and roads.

\section{Modeling of indicators of manufacturability}

As studies show, changes in the manufacturability of construction products almost always proportionally affect the costs of labor and machine time, and in many cases, the costs of material and financial resources. In this regard, expressions of the following type can be used:

$$
P=\frac{Q}{G}
$$

where Q, G - design and actual indicator of the labor intensity of manufacturing products, respectively.

Here, a certain simplification is allowed, and the value of $Q$ is considered as a reference in which a comprehensive maximum increase in the manufacturability of construction products has been taken into account at the stage of calculation (design) due to the high factory readiness of structures and products, their enlargement at the construction site, efficient use of vehicles, effective connection structures and units among themselves, etc.

At $G \leq Q$, the manufacturability index $P \geq 1$, which indicates the high manufacturability of the product. At the same time, for $G>Q$, index $P<1$, which indicates that the production technology does not correspond to the design requirements.

With regard to a group of objects, the manufacturability indicator can be defined as

$$
P=\frac{\sum_{i=1}^{n} G_{i} \cdot Q_{i}^{2}}{\sum_{i=1}^{n} Q_{i} \cdot G_{i}^{2}}
$$

where $Q_{i}, G_{i}$ - calculated (design) and actual indicator of the labor intensity of the construction of the $i$-th object, respectively.

$$
i=\overline{1, n}
$$

Values of $Q_{i}^{2}$ and $G_{i}^{2}$ caused by taking into account the indicator of their frequency in the form of expressions $\frac{Q_{i}}{\sum_{i=1}^{n} Q_{i}}$ and $\frac{G_{i}}{\sum_{i=1}^{n} G_{i}}$, which must be included in the calculation when determining the integral indicator of manufacturability.

The sequence of determining the integral indicator of the manufacturability of construction products as a whole for the renovation zone includes the following stages:

1. Establishing the structure of the objects of the renovation zone with their separation into groups - new residential buildings, reconstructed residential buildings, industrial facilities, infrastructure facilities - preschool and school buildings, medical institutions, etc.

2. Allocation, if necessary, of objects of sub-groups of buildings and structures of the same type in each group - tower-type residential buildings, large-panel single-section, large-panel multi-section residential buildings, residential buildings with a monolithic reinforced concrete frame, etc. 
3. Determination of calculated (design) and actual indicators of labor intensity for each group and subgroup of objects. Here you should take into account the peculiarities of performing mechanized work and work performed manually.

For work with full mechanization, labor costs can be equated to the costs of machine time. In the case of incomplete mechanization of production processes, it is advisable to carry out a comparative analysis of the productivity of the leading machine and the corresponding link of workers. For greater objectivity, information on the achieved productivity of teams at similar sites should be used. When analyzing labor costs, in addition to the design values, the standard values established by the State Itemized Cost Estimate Standards or Federal Unit Rates can be used.

4. Determination of manufacturability indicators for all subgroups of buildings and structures of the same type using expression (4).

5. Determination of the general indicator of manufacturability of objects of each group using expression (4).

6. Determination of the integral indicator of manufacturability of all objects of the renovation zone using expression (4).

\section{Conclusions}

Nowadays, urban renovation includes not only residential areas, but also industrial zones. At the same time, each renovation area is distinguished by a wide variety of residential and non-residential buildings, infrastructure facilities. In this regard, to assess the level of achievement of design solutions in the process of renovation of buildings and structures, it is recommended to use the system of indicators of the manufacturability of construction products.

As a basic indicator of the manufacturability of buildings and structures, it is advisable to take the characteristics of labor costs and machine time, since it is these indicators that adequately respond to changes in the technology of work, the observance of the regulations of which ensures the achievement of the design quality of construction products.

\section{References}

1. Bulgakov S.N. Technological innovations in the investment and construction complex. M: Publishing house of RAASN, 1998.

2. Kapshuk O.A., Shalenny V.T. The manufacturability of varieties of modern collapsible formwork systems. // Engineering and construction journal. - 2014, No. 7 (51).

3. Kievsky L.V. Planning and organization of construction of engineering communications. - M: SvR-ARGUS, 2008.

4. Klyueva N.V. Resource-energy-saving constructive system of residential and public buildings with a given level of constructive safety. // N.V. Klyueva, V.I. Kolchunov, A.S. Bukhtiyarova // Industrial and civil engineering - 2014, No. 2

5. Oleinik P.P. Renovation of the housing stock of the first industrial generation. // Mechanization of construction - 2017, No. 10.

6. Oleinik P.P. Scientific and technical progress in the construction industry. - M: ASV Publishing house, 2019.

7. Poltavtsev S.I., Monfred Yu.B., Volga V.S. Manufacturability of residential buildings. M: Stroyizdat, 1992.

8. Development of the city. Collection of scientific papers / edited by L.V. Kievsky. - M: SvR-ARGUS, 2005. 
9. Construction and reconstruction of buildings and structures of urban infrastructure. Vol 1. Organization and technology of construction, scientific reference manual / edited by V.I. Telichenko. - M: ASV Publishing house, 2003.

10. Surin G.D. Priority of building up areas. // Industrial and civil engineering, 2006, No. 10.

11. Surin G.D. Priority of engineering support for development and reconstruction areas. // Industrial and civil engineering, 2005, No. 8.

12. Technology of erection of prefabricated buildings / edited by A.A. Afanasyev, - M: ASV Publishing house, 2000

13. Technological processes in construction. Books 1-10. M: ASV Publishing house, 2016.

14. Chulkov V.O., Rakhmanov E.K., Rodin A.E. Modeling and optimization of organizational and technological solutions for the reorganization of a construction object. // Industrial and civil engineering, 2005, No. 10. 